\title{
Role of Carboxy Terminal Propeptide of Type I and Type III Procollagen (PICP and PIIICP) Toward the Severity Degree of Mitral Valve Regurgitation in Children's Rheumatic Heart Disease
}

\author{
Renny Suwarniaty ${ }^{1,2 \star}$, Mohammad Saifur Rohman ${ }^{3}$, Tinny Endang Hernowati ${ }^{4}$, Wisnu Barlianto ${ }^{2}$ \\ ${ }^{1}$ Doctoral Program of Medical Science, Faculty of Medicine, Universitas Brawijaya, Malang, Indonesia; ${ }^{2}$ Department of \\ Pediatrics, Faculty of Medicine, Universitas Brawijaya, Malang, Indonesia; ${ }^{3}$ Department of Cardiology and Vascular Medicine, \\ Dr. Saiful Anwar General Hospital, Faculty of Medicine, Universitas Brawijaya, Malang, Indonesia; ${ }^{4}$ Department of Clinical \\ Pathology Faculty of Medicine, Universitas Brawijaya, Malang, Indonesia
}

Edited by: Slavica Hristomanova-Mitkovska Citation: Suwarniaty R, Saifurrohman M, Hernowati TE, Barlianto W. Role of Carboxy Terminal Propeptide of Type I and Type III Procollagen (PICP and PIIICP) Toward the Severity Degree of Mitral Valve Regurgitation in Children's Rheumatic Heart Disease. Open Access Maced J Med Sci. 2020 Sep 30; 8(B):802-806. https://doi.org/10.3889/oamjms. 2020.4798 Keywords: Heart; Procollagen; PICP; PIIICP; Rheumatic *Correspondence:Renny Suwarniaty, Department of Malang, Indonesia E-mail: suwarrenny Brailco, Received:07-May-2020 Revised: 23-Jun-2020 Revised: $23-J 4 n-2020$ Copyright: ๑ 2020 Renny Suwarniaty, Mohammad Saifur Rohman, Tinny Endang Hernowati, Wisnu Barlianto Funding: This research was financially supported by the Direktorat Jenderal Pendidikan Tinggi, Indonesia Competing Interests: The authors have declared that $n$ competing interests exist Open Access: This is an openative Commons AtributiononCommercial 4.0 International License (CC BY-NC 4.0)

\begin{abstract}
BACKGROUND: Rheumatic heart disease (RHD) is recognized as a heart disease that occurs as a result of sequelae in acute rheumatic fever (ARF), characterized by the occurrence of defects in the heart valves. The most common manifestation of childhood RHD is mitral regurgitation (MR). The role of inflammation and oxidative stress in RHD also involves several components consisting of carboxy-terminal pro-peptide of Type I procollagen (PICP) and carboxy-terminal pro-peptide of Type III procollagen (PIIICP).

AIM: The aim of this study was to know whether PICP and PIIICP can be used to measure the severity level of mitra valve regurgitation

METHODS: This research is considered as descriptive-analytic research, and using cross-sectional analysis. Forty RHD patients underwent echocardiographic examinations to measure Wilkin and effective regurgitant orifice area scores. Patients were classified into ARF without valve abnormalities, mild, moderate, and severe MR. PICP and PIIICP were with ARF through venous blood and ELISA was examined. Data were analyzed by employing SPSS 22 with $p=0.05$ ). Wilkins scores and PICP levels have a regression coefficient of 0.296 with a $p$-value of 0.032 .

RESULTS: There was a significant difference in PICP level among the studied sample groups with a $p=0.012$ $(p<0.05)$, with insignificant difference in PIIICP level among sample groups with a $p=0.083$, greater than $\alpha=0.05$ $(p>0.05)$. Wilkins scores and PICP level have a regression coefficient of 0.296 with a $p=0.032(p<0.05)$, while PIIICP level has a regression coefficient of 0.093 with a $p=0.568(p>0.05)$.

CONCLUSION: There is no significant increase indicated on PIIICP level, but PICP level indicates a significant increase in RHD group with severe mitral valve abnormalities. PICP can be used to measure the severity level of mitral valve regurgitation.
\end{abstract}

\section{Introduction}

Rheumatic heart disease (RHD) becomes a major cause of heart valve disease worldwide and is a leading cause of cardiovascular death in children at developing countries [1]. According to the World Health Association Report [2], the annual incidence of acute rheumatic fever (ARF) in children (age 5-14 years) reaches to $300,000-350,000$. In addition, there are around $1.5 \%$ mortality rates of RHD sufferers with carditis annually [2]. The mitral valve was the most commonly affected part of the heart valve $( \pm 65-70 \%)$, followed by the aortic valve $( \pm 25 \%)$, while the tricuspid and pulmonary valves were rarely affected. The most common valve abnormality in children concerns with mitral valve regurgitation mitral regurgitation (MR) [3].

Group A beta-hemolytic streptococcus (GABHS) polysaccharides and cardiac valve glycoprotein have similarities that are both considered as $\mathrm{N}$-acetyl glucosamine. This structural similarity (molecular mimicry) causes a cross-reaction between GABHS and heart valve tissue [4]. Heart valve tissue that was not originally an antigen (non-self-antigen) turned into an antigen (self-antigen), thereby triggering a response to humoral immunity [5] and cellular immunity which in turn triggers inflammation [6].

Inflammation and oxidative stress in RHD involve several components, including carboxy-terminal propeptide of Type I procollagen (PICP) and carboxyterminal propeptide of Type III procollagen (PIIICP) [7]. Increased serum of PICP and PIIICP has been found in various heart diseases such as cardiomyopathy, hypertensive heart disease, adult heart failure, and adult rheumatic mitral valve disease [8], [9], [10]. However, relevant studies were unfortunately limited to examining the levels of PICP, PIIICP in pediatric RHD patients, and the relationship between PICP and PIIICP levels to the severity of mitral valve regurgitation in pediatric RHD. 
Echocardiography serves as the gold standard to determine the severity of valve involvement in RHD. Nevertheless, such examination has been widely unavailable; thus, an alternative examination is proposed as a predictor of valve damage degree in patients with RHD. One developed method is the examination of biomarker remodeling of P1CP and PIIICP [11].

Based on this background, the researchers initiated to examine the relationship between increased carboxy-terminal propeptide of Type I and Type III procollagen (PICP and PIIICP) to the severity of mitral valve regurgitation in pediatric RHD patients.

\section{Materials and Methods}

This research is considered an observational analytic study with a cross-sectional method. In this study, there were four groups of cases, including pediatric RHD patients with mild, moderate, and severe mitral valve regurgitation and one group of patients with rheumatic fever who did not experience valve abnormalities. This research was conducted at Children Cardiology Clinic at General Hospital Dr. Saiful Anwar Malang and Biomedical Laboratory, Faculty of Medicine, Universitas Brawijaya. This research was conducted on July 2019 until fulfilling the number of collected samples in December 2019 with ethical clearance number 400/136/K.3/302/2018.

\section{Sample collection}

The study sample involved pediatric patients (aged between 5 and 17 years) who were diagnosed with RHD and underwent outpatient care at Children Cardiology Polyclinic. All study subjects had agreed and signed the research informed consent.

Sampling in this study employs a purposive sampling method with exclusion criteria for patients experiencing inflammation or other acute infections other than ARF or RHD.This research used formula Dahlan, 2010 [12].

$$
\mathrm{n}=\left(\frac{Z \alpha+Z \beta}{0.5 \operatorname{Ln}((1+r) /(1-r))}\right)^{2}+3
$$

Sampling of peripheral blood was performed in the Clinical Pathology Laboratory (Central Laboratory) of RSSA by laboratory personnel. The blood volume administered in each study sample was $3 \mathrm{cc}$ for ELISA examination. Blood was inserted into the EDTA vacutainer tube, stored in a cool box, and kept at a temperature of $4^{\circ} \mathrm{C}$ [13].

\section{Echocardiography}

Based on echocardiographic results, forty patients were diagnosed with RHD based on the 2012 Echo World Heart Federation criteria by determining the severity of mitral valve regurgitation. Morphological mitral valve features are well-visualized on standard 2D echocardiography. This research used Vivid-q 2D echocardiography [14].

The severity of mitral valve regurgitation is determined by transthoracic echocardiography. The severity level is divided into three which are: mild, moderate, and severe by utilizing quantitative and semi-quantitative methods based on the European Association of Echocardiography (2010) recommendations to assess valvular regurgitation (mitral and tricuspid regurgitation), by considering the value of effective regurgitant orifice area, volume regurgitant, and venous contracta. Inflammation which occurs in the mitral valve is echocardiographically assessed by administering the Wilkins Score.

The morphology of the mitral valve was assessed as described by Wilkins et al., based on a semiquantitative grading of mitral valve leaflet mobility, thickening, calcification, and subvalvular thickening, each on a scale of $0-4$, with higher scores representing the more abnormal structure. The total echocardiographic score was obtained by adding the scores of each of these individual components. According to this system, a score of 0 would be a totally normal valve, whereas a score of 16 would represent an immobile valve with fibrosis involving the entire leaflet and subvalvular apparatus and severe superimposed calcification [15], [16].

\section{Biochemical marker examination}

The technique to measure PICP and PIIICP levels in this study is ELISA with a sandwich technique. PICP level was measured by ELISA paint kit of SEA570Hu, while PIIICP level was measured by paint kit of CEA963Hu [13].

\section{Statistical analysis}

The collected data were analyzed by employing SPSS 22 software and multiple linear regression analysis to determine the effect of PICP and PIIICP levels on the severity of mitral valve regurgitation in pediatric RHD patients.

\section{Results}

The characteristics of the study involving 40 research samples are presented in Tables 1 and 2 by age, height, weight, total Wilkin Scores, and sex, respectively. Based on Table 1, the data indicate that 
the lowest mean age was found in the severe group of $9.7 \pm 2.2$ years and the oldest average age was found in the moderate group which was $12.7 \pm 2.3$. The researcher performed ANOVA indicating $p=0.148$ $(p>0.05)$, marking that there were no differences in age characteristics between groups.

Table 1: Characteristics of the study sample by age, height, weight, and total Wilkin score

\begin{tabular}{|c|c|c|c|c|}
\hline \multirow[t]{2}{*}{ Group } & \multicolumn{4}{|c|}{ Characteristic } \\
\hline & Age & Height & Weight & Wilkin score \\
\hline Normal & $10.2 \pm 2.2$ & $135.1 \pm 13.4$ & $32.7 \pm 15.4$ & $0 \pm 0$ \\
\hline Mild & $11.4 \pm 3.9$ & $140.2 \pm 15$ & $38.2 \pm 11.4$ & $0 \pm 0$ \\
\hline Moderate & $12.7 \pm 2.3$ & $140.2 \pm 15.1$ & $37.3 \pm 21.4$ & $1.6 \pm 1.1$ \\
\hline Severe & $9.7 \pm 2.2$ & $140 \pm 6.6$ & $31.9 \pm 6.1$ & $2.7 \pm 1.5$ \\
\hline $\mathrm{p}$-value & 0.148 & 0.799 & 0.363 & 0.000 \\
\hline
\end{tabular}

Likewise, the characteristics of height and weight obtained $p$-value of more than 0.05 ( $p>0.05$ ). The results of the test proved that there were no significant differences in the characteristics of age, height, and weight between the studied sample groups.

Table 2: Characteristics of study samples by sex

\begin{tabular}{llll}
\hline Group & Sex & & p-value \\
\cline { 2 - 3 } & Male (\%) & Female (\%) & \\
\hline Normal & $5(55.6)$ & $4(44.4)$ & 0.175 \\
Mild & $5(38.5)$ & $8(61.5)$ & \\
Moderate & $5(55.6)$ & $4(44.4)$ & \\
Severe & $1(11.1)$ & $8(88.9)$ & \\
Total & $16(40)$ & $24(60)$ & \\
\hline
\end{tabular}

Table 2 shows that, based on the characteristics of total Wilkin score, $p<0.05$ which indicates the difference in characteristics of total Wilkin score. Both normal and mild groups have the lowest total score. The highest total Wilkin score was found in the severe group.

Table 2 shows the characteristics of study samples by sex which clearly indicates that the majority of the study samples are female. The result of Chi-square test demonstrating $p=0.175(p>0.05)$ proves that there are no differences in sex characteristics between groups.

When compared among the mild, moderate, and severe mitral valve regurgitation in children with $\mathrm{RHD}$, the data indicate that the highest average of PICP levels is found in the severe group, which are significantly different from the mild and moderate groups.

Based on the ANOVA test, Figure 1 shows that the $p=0.012,(p<0.05)$. Thus, the researcher concludes that there are significant differences in PICP levels among the studied sample groups.

Figure 2 shows that analysis using the ANOVA test indicates $p=0.083$, which is greater than $p=0.05$ $(p>0.05)$. Therefore, it is concluded that there is no significant difference in PIIICP level among the studied sample groups.

Average PIIICP levels increase in the group of children with RHD, in mild, moderate, and severe group. However, increasing PIIICP levels do not occur significantly.

PICP level indicates a regression coefficient of 0.034 with a $p=0.007(p<0.05)$, concluded that PICP level has a significant effect on the variable of valve

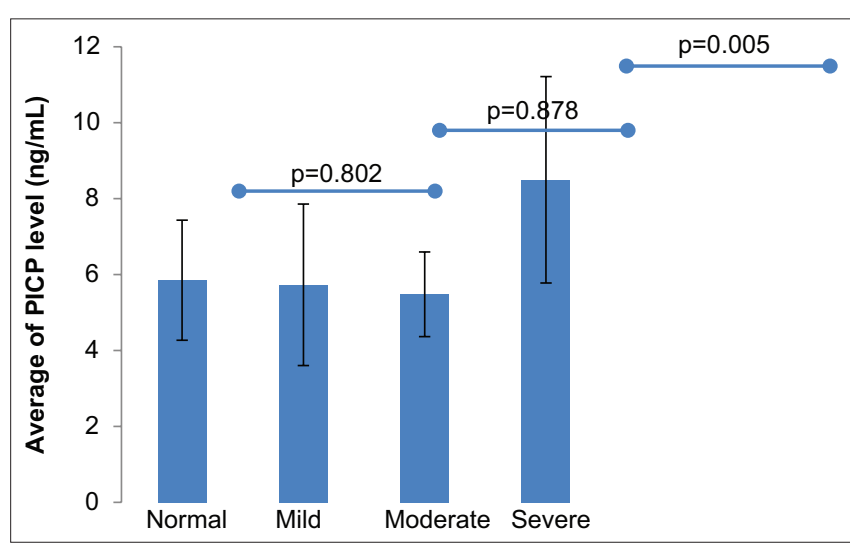

Figure 1: PICP levels of Mitral Valve Regurgitation in Children's RHD

regurgitation in children with RHD. Meanwhile, the level of PIIICP has a regression coefficient of $0.0-0.008$ with a $p=0.303(p>0.05)$.

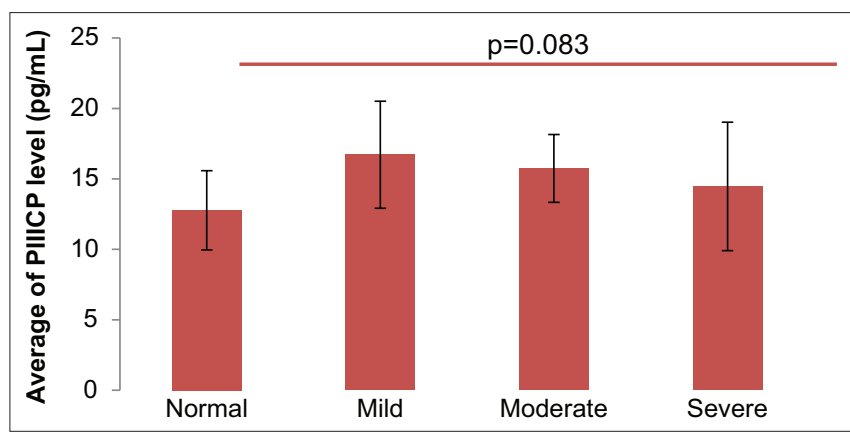

Figure 2: PIIICP level of Mitral Valve Regurgitation in Children's RHD

Wilkins score and PICP level have a regression coefficient of 0.296 with a $p=0.032(p<0.05)$, concluded that PICP level has a significant effect on Wilkins scores in children with RHD. Meanwhile, PIIICP level has a regression coefficient of 0.093 , with a p-value of 0.568 $(p>0.05)$.

\section{Discussion}

The sex distribution in this study demonstrates the prevalence of RHD cases which is higher in females than in males but does not show a significant difference. The proportion of RHD based on sex is slightly different from the proportion based on registry data in Australia (1997-2010), indicating approximately 65.8-71.1\% of female. Although there are differences in numbers, similarity has been evident; emphasizing that female sex is higher than male.

The results of the study postulate that there are no significant differences in the characteristics of age, height, and weight among the studied sample groups. Thus, such finding indicates that the research sample is homogeneous among groups.

Cardiac extracellular matrix (ECM) consists of collagen Type I (85\%) and Type III (11\%). Type I and 
III collagen are synthesized by cardiac fibroblasts. Cardiac fibroblasts are collagen-producing cells located in the human heart inhibited by mRNA cells for the formation of collagen I and III. Fibrillar collagen is synthesized as procollagen, further broken down by specific proteinases into carboxy $(\mathrm{C})$ - and amino $(\mathrm{N})$ - terminal propeptides. N-terminal Type I or Type III collagen propeptides (PINP and PIIINP) and C-terminal propeptides (PICP and PIIICP) are utilized as a Type I or III collagen synthesis marker. After splitting into propeptides, the triple helix chain will form fibers. During the inflammatory process in RHD, the released cytokines cause differentiation of valvular interstitial cells (VCls) to activate myofibroblasts. VCls are regarded as the most cells in valves producing ECM proteins, including collagen [10].

The role of carboxy-terminal propeptide of Type I $(\mathrm{PICP})$ is released into the bloodstream during Type I collagen synthesis. Therefore, PICP is considered as a marker of Type I collagen synthesis. Likewise, PIIICP is released into the circulation during the synthesis of Type II collagen, which is $85 \%$ higher than PIIICP, causing PICP to be more significant than PIIICP.

A significant relationship to PICP in this study is similar to previous studies [10]. In the study, plasma carboxy-terminal propeptide of Type I (PICP) was indicated to increase concentration in MS and MR patients compared to the control groups. PICP levels are strongly related to the mitral valve area in MS. Whereas in MR, these parameters are related to left ventricular diastolic pressure and systolic diameter [10]. PICP level has a positive influence on the severity of valve regurgitation in children with $\operatorname{RHD}(p=0.007$, $p<0.05)$. This finding indicates that PICP level is beneficial to predict the severity of valve regurgitation.

The prior study emphasized that the ratio of Type I/III collagen in the mitral valve and aortic valve in 10 patients with RHD, significantly increased $(p=0.001)$. The amount of collagen was higher in the mitral valve than in the aortic valve $(p=0.01)$, where the ratio of Type I/III collagen was lower in the normal mitral valve compared with the aortic valve $(p=0.001)$. Increased collagen in mitral and aortic valves for patients with RHD was mainly due to an increase in Type 1 collagen [17].

Type 1 and Type 3 collagen are found in cardiac tissue. Although Type 1 collagen is predominant in myocardium, Type 3 collagen is more specific to heart tissue [10], causing PIIICP to have no significant relationship to the degree of heart damage.

In addition, carboxy-terminal propeptides of Type III collagen (PIIICP) are not completely broken down during the conversion of pro-Type III collagen to Type III collagen, by considering the fact that it requires longer steps, removed during fiber degradation. Consequently, the ratio among the released number of Type III collagen, PIIICP, and PIIINP molecules is equivalent [18], causing an insignificant level of PIIICP.
The results indicate a significant difference in the total Wilkin scores among sample groups. Wilkins score includes four following parameters: Mitral valve thickening, valve mobility, valve calcification, and subvalvular thickening. Inflammatory parameters are positively related to biomarkers in the ECM [19], [20]. In this study, PICP and PIIICP levels escalate according to Wilkins score calculations.

Research about Wilkin score and mitral stenosis (MS) showed that in patients with MS, especially asymptomatic patients, the conjunction of the biomarkers score (BNP, tenascin-c, copeptin, and hs-CRP) and Wilkin's score provided higher prognostic value [21].

\section{Conclusion}

There is no significant increase on PIIICP level; on the other hand, PICP level indicates a significant increase in RHD group with severe mitral valve abnormalities. PICP level also has a significant effect on Wilkins scores in children with RHD, highlighting that $\mathrm{PICP}$ level is advantageous to predict the severity level of valve regurgitation.

\section{Acknowledgments}

We would like to thank Saiful Anwar Malang Hospital Laboratory for helping with research sampling and thank the biomedical laboratory for assisting in the ELISA examination.

\section{References}

1. World Health Organization. Rheumatic Fever and Rheumatic Heart Disease, Report of a WHO Study Group. Geneva: World Health Organization, Technical Report Series, No.923; 2011.

2. World Health Organization. The Global Burden of Disease, Report of a WHO Study Group. Geneva: World Health Organization, Technical Report Series, No.815; 2014.

3. Carapetis JR, Beaton A, Cunningham MW, Guilherme L, Karthikeyan G, Mayosi BM, et al. Acute rheumatic fever and rheumatic heart disease. Nat Rev Dis Primers. 2016;2:1504. PMid:27188830

4. Goldstein I, Rebeyrotte P, Parlebas J, Halpern B. Isolation from heart valves of glycopeptides which share immunological properties with Streptococcus haemolyticus group a polysaccharides. Nature. 2008;219:866-8. https://doi. org/10.1038/219866a0

5. Delunardo F, Scalzi V, Capozzi A, Camerini S, Misasi R, Pierdominici $\mathrm{M}$, et al. Stresptococcal-vimentin cross reactive 
antibodies induce microvascular cardiac endhothelial proinflammatory phenotype in rheumatic heart disease. Clin Exp Immunol. 2013;173(3):419-29. https://doi.org/10.1111/ cei. 12135

\section{PMid:23663103}

6. Toor D, Vohra H. Immune responsiveness during disease progression from acute rheumatic fever to chronic rheumatic heart disease. Microbes Infect. 2012;14(12):1111-7. https://doi. org/10.1016/j.micinf.2012.07.003

7. Lopez B, Gonzales A, Diez J. Circulating biomarkers of collagen metabolism in cardiac diseases. Circulation. 2010;121(14):1645-54.

PMid:20385961

8. Nagase $H$, Visse R, Murphy G. Structure and function of matrix metalloproteinases and TIMPs. Cardiovasc Res. 2006;69(3):56273. https://doi.org/10.1016/j.cardiores.2005.12.002 PMid:16405877

9. Martos R, Baugh J, Ledwidge M, O'Loughlin C, Conlon C, Patle $A$, et al. Diastolic heart failure: Evidence of increased myocardial collagen turnover linked to diastolic dysfunction. Circulation. 2007;115(7):888-95. https://doi.org/10.1161/ circulationaha.106.638569

PMid: 17283265

10. Banerjee T, Mukherjee S, Ghosh S. Clinical significance of markers of collagen metabolism in rheumatic mitral valve disease. PLoS One. 2014;9(3):e90527. https://doi.org/10.1371/ journal.pone.0090527

PMid:24603967

11. Vijayalakshmi IB, Vishnuprabvu RO, Chitra N, Rajasri R, Anuradha TV. The efficacy of echocardiographic criterions for the diagnosis of carditis in acute rheumatic fever. Cardiol Young. 2008;18(6):586-92. https://doi.org/10.1017/ s1047951108003107 PMid: 18845020

12. Dahlan MS. Besar Sampel Dan Cara Pengambilan Sampe Dalam Penelitian Kedokteran Dan Kesehatan. Jakarta: Salemba Medika; 2010.

13. Beniwal R, Bhaya M, Panwar RB, Panwar S, Singh A. Diagnostic criteria in rheumatic heart disease. Global Heart. 2015;10(1):812. https://doi.org/10.1016/j.gheart.2014.07.001
PMid:25754572

14. Guilherme L, Kalil J. Rheumatic fever and rheumatic heart disease: Cellular mechanisms leading autoimmune reactivity and disease. J Clin Immunol. 2010;30(1):17-23. https://doi. org/10.1007/s10875-009-9332-6

PMid: 19802690

15. Lancellotti P, Moura L, Pierard LA, Badano L, Zamorano JL. European association of echocardiography recommendations for the assessment of valvular regurgitation. Part 1: Aortic and pulmonary regurgitation (native valve disease). Eur $\mathrm{J}$ Echocardiogr. 2010;11(3):307-32. https://doi.org/10.1093/ ejechocard/jeq031

PMid:20375260

16. Wilkins GT, Weyman AE, Abascal VM, Block PC, Palacios IF. Percutaneous balloon dilatation of the mitral valve: An analysis of echocardiographic variables related to outcome and the mechanism of dilatation. $\mathrm{Br}$ Heart J. 1988;60(4):299-308. https://doi.org/10.1136/hrt.60.4.299 PMid:3190958

17. Lijnen PJ, Maharani T, Finahari N, Prihadi JS. Serum collagen markers and heart failure. Cardiovasc Haematol Disord Drug Targets. 2012;12(1):51-5. https://doi. org/10.2174/187152912801823147 PMid:22524171

18. Jensen LT, Host NB. Collagen: Scaffold for repair or execution Cardiovasc Res. 2007;33(3):535-9 PMid:9093523

19. Aloui S, Zidi W, Ouali S, Guizani I, Hadj-Taieb S, Mourali MS, et al. Association of matrix metalloproteinase 3 and endogenous inhibitors with inflammatory markers in mitral valve disease and calcification. Mol Biol Rep. 2018;45(6):2135-43.

PMid:30302620

20. Seo WY, Kim JH, Baek DS, Kim SJ, Kang S, Yang WS, et al. Production of recombinant human procollagen Type I C-terminal propeptide and establishment of a sandwich ELISA for quantification. Sci Rep. 2017;7:15946.

21. Mahfouz RA, Eldawei K, Elawady W, Dewedar A. Biomarkers score for patients with mitral stenosis: A useful conjunction with Wilkins's score for early intervention. Heart Res Open J. 2015;2(4):118-25. https://doi.org/10.17140/hroj-2-121 